\title{
Robotic in the field of kidney Transplant Surgery
}

\section{Ahmed M. M. A. Elsherief ${ }^{1}$, Atef G. Abdelwahaab ${ }^{1}$, Ahmed R. Hamady ${ }^{1}$, Ahmed M. Abd Elhamid ${ }^{1}$, Nasreldin Abdelaal Mohammed $^{2}$}

1-Urology Department, Faculty of Medicine, Sohag University . 2- Urology Department, Faculty of Medicine, Assuit University

\begin{abstract}
:
Currently, minimally invasive surgical treatment has ended up the usual approach in an extensive style of interventions.

Robotic surgical treatment is an emerging field specifically, in a laparoscopic surgical operation. Many agencies have manufactured robotic structures with different skills and fee tags.

With robotic systems as the da Vinci Surgical System (daVSS), the power of organ transplantation is carried out with minimally invasive fashion.

Da Vinci device received its recognition from its advantages, within the factor of the most effective ergonomic surroundings for the operator, and a 3D vision that restores the hand-eye coordination misplaced in the laparoscopic approach.

Within the kidney transplant area, the robotic-assisted surgery applied in donor nephrectomy and recipient kidney transplants.

Every other use for the robotic within the field of kidney transplantation, that it's been described in recipients for the remedy of complications related to surgery, and radical prostatectomy in kidney transplant recipients with higher effects
\end{abstract}

Keywords: Robotic, kidney transplant, RAKT

\section{Abbreviation:}

daVSS: da Vinci Surgical System

RADN: Robotic Assisted donor nephrectomy

3-D: 3-dimensional

KT: Kidney Transplant

LDN:Laparoscopic donor nephrectomy

WIT: Warm ischemia time

Starting of robotic in transplant surgical treatment

In the latest many years, minimally invasive surgical treatment has received considerable significance and end up a first-class approach in a huge kind of intervention.

Also besides, traits consist of robot surgery it is an emerging subject specifically, in the laparoscopic surgical procedure. Many organizations have manufactory some robot structures with exclusive talents and fee tags.

The rapid improvement and development in the device along with camera structures, insufflators, devices, and surgical tactics for minimally invasive surgeries have modified interventions during the last few years.

The drawbacks of traditional laparoscopic surgical operations are conquered by the usage of the robotic systems for robot-assisted surgery and consist of overcome decreased visualization, limited range of movement, and physiological tremor of the health care professional. (1) Robotic-assisted surgical procedure (RAS) is safe and possible in performing a tough and 
complex technique, (2) like organ transplantation than with conventional laparoscopic strategies, they considered unsuitable for minimally invasive surgical treatment. ${ }^{(3)}$

But, with robot systems much likes the da Vinci Surgical machine (Intuitive Surgical, Sunnyvale, CA, USA), the power of surgeons has significantly elevated and organ transplantation is accomplished with minimally invasive style. ${ }^{(4)}$

\section{Robotic in the area of kidney transplant}

Inside the kidney transplant discipline, the robot-assisted surgical operation utilized in donor nephrectomy and recipient kidney transplants

\section{Robotic-Assisted donor nephrectomy (RADN)}

Many advantages provided by means of Living kidney transplantation over deceased one within the kind of immediate characteristic of the allograft, superior lengthy-time period patient and graft survival, much less ready time, and consequently the opportunity of preemptive transplantation. ${ }^{(5)}$

Over 50 years, open donor nephrectomies had been the first-rate method to urge the graft, till, Ratner et al who implement laparoscopic donor nephrectomy in 1995 . (6) The laparoscopic method provides benefits for donor nephrectomy with less blood loss, pain, improved aesthetic consequences, and early convalescence.

The laparoscopic approach now could be enormous and is that the commonest approach for acting donor nephrectomies, main to encouraging living donation with a variety of the donor pool. ${ }^{(7,8)}$

The Da Vinci Surgical System (Intuitive Surgical Inc.), approved by the US Food and Drug Administration; In 2000, as one of the mini-invasive strategies that integrate the robotic method and computer imaging that assist within the microsurgery subject, for its use inside the US.

$\mathrm{Da}$ Vinci system received its recognition from its advantages compared with open surgical operation, superior ergonomic surroundings for the operator, and a three-Dimensional (3D) imaginative and prescient device that restores the hand-eye coordination misplaced in laparoscopic technique. $(\mathbf{9 , 1 0 )}$

The University of Illinois at Chicago published the primary series of donor nephrectomies with robotic-assisted, in 2001. ${ }^{(11,12)}$ Since then, there has been an upward thrust in the use of the da Vinci machine in many facilities with thinking about the robot as a secure and possible technique with wonderful outcomes with less morbidity compared with the laparoscopic approach. ${ }^{(\mathbf{1 0}, \mathbf{1 3})}$

Janki et al reported their series ${ }^{(\mathbf{1 4})}$ that show left-sided RADN is secure and viable with better consequences for the donor, additionally for the recipient and post-operative graft survival after 3 months.

Although the RADN approach can also take long operative time; however, 3D imaging, higher tool maneuverability, and comfort are acquired.

The time element will enhance swiftly with extended experience and nicelyskilled surgeons and approximate mimic the time of different techniques. (14)

Bhattu et al. ${ }^{(15)}$ achieved their trial that turned into a randomized controlled one with comparing RADN to laparoscopic donor nephrectomy (LDN). They conclude that RADN is safe and with low morbidity than LDN. With the utilization of the robot method, ease technical use and higher renovation of a longer length of the renal artery on the right side has obtained while left-sided is related to longer warm ischemia time (WIT) 
however with none negative impact on graft outcome.

Despite the fact that RADN appears safe and viable; however, it had been limited to certain case series, because of lengthy WIT and higher prices, the system appears to be, constrained to high-quantity centers.

\section{Robotic Kidney Transplantation}

Kidney transplantation is the 'gold widespread' approach of treatment for patients with end-stage renal disease because it increases survival and improves the same old and amount of lifestyles. ${ }^{(16)}$

To this point, the open method has been the gold preferred in KT, in spite of its invasiveness and excessive morbidity.

Minimally invasive surgical treatment is a superb opportunity method to the open approach in decreasing morbidity.

In a Kidney transplant, the minimally invasive methods consist of traditional laparoscopic with both (transperitoneal or retroperitoneal), robotic-assisted, also minimal open -access. ${ }^{(17)}$

In standard, the minimally invasive surgical operation provides enormous benefits to sufferers, in the kind of better peri- and postoperative outcmes, as regards brief hospital stay, less postoperative pain, short convalescence period, minimal wound infections, and better cosmetic consequences. ${ }^{(18)}$

Many blessings of the robot techniques in the technical aspect as in reconstructive and vascular surgical treatment. As within the literature, it lets in the overall performance of an exquisite vascular anastomosis and ureteric reimplantation. ${ }^{(\mathbf{1 9 - 2 2})}$

Giulianotti et al. ${ }^{(23)}$ did the primary pure RAKT in 2010 after they executed in a morbidly obese affected person within the USA.

The first European case of RAKT, posted by means of Boggi et al. (24), throughout which vascular anastomosis of the graft achieved by using the usage of the robotic wherein ureterovesical anastomosis become done with the aid of open manner!

Thereafter, the RAKT technique was standardized in 2014, through Menon et al. ${ }^{(25)}$ in their study on 25 patients who underwent RAKT with a followup time of 6 months. Accompanied by means Breda et al. (20) and Doumerc et al. (26) in 2015, wherein they did RAKT that became finished by using the use of the robotic for the first time in Europe.

In step with the literature, robot surgical procedure presents many blessings in technical and useful issue while applied in KT. in particular in the narrow and deep field and whilst delicate dissection and satisfactory suture are wished; those are because of the benefits of robotic as regard to $3 \mathrm{D}$ vision, freedom of movement in seven degrees, amazing magnification, and elimination of tremor. (22) Therefore the use of the robot in surgical treatment helps in doing very sensitive vascular anastomosis and ureteric reimplantation.

Moreover, as many centers are now doing RAKT, it considers being secure and possible surgical procedures in experts in KT and robot surgeries. ${ }^{(27)}$

Notwithstanding the advantages of robot surgical operation, some dangers are present like extended time of surgical operation and ischemia time that cause graft harm and postpone graft feature. $(17,27)$

Marzouk et al. ${ }^{(17,28)}$ published their experience that shows anastomosis time more than $29 \mathrm{~min}$ increases the incidence of delayed graft function within the postoperative period. This agreement with the results of Weissenbacher et al. ${ }^{(24)}$ shows prolonged ischemia time more than $30 \mathrm{~min}$ hurts patients and graft survival, therefore RAKT better only did with expert surgeons in high-volume centers 
to avoid kidney injury from long ischemia time.

One of the critical steps in RAKT is allograft instruction inside the Back table to facilitate the orientation of the graft and reduce blood loss after reperfusion.

Lately, Tsai et al. ${ }^{(29)}$ published their first experiences in retroperitoneal RAKT with excellent consequences.

Obese patients have a high rate of surgical site infections, in series of Laplace et al. ${ }^{(30)}$ on 100 patients that RAKT has been done show that about ninety-nine \% immediate renal grafts characteristic become attained with absent surgical site infections and outcomes were nearly like non-obese recipients. ${ }^{(31)}$ This research highlights the significance of enforcing a substitute surgical technique in obese kidney transplant recipients.

Another uses for robot inside the subject of kidney transplantation, that it has been defined in recipients for the treatment of complications associated with surgery, like cases of lymphocele, pyeloureterostomy for ureteral stricture (32), partial nephrectomy simply in case of mass within the allograft ${ }^{\text {(33), }}$, graft nephrectomy by using transabdominal approach $^{(34)}$, and radical prostatectomy for prostate cancer treatment in kidney transplant recipients ${ }^{(35)}$ with higher outcomes

\section{References}

1. Giulianotti PC, Coratti A, Angelini M, Sbrana F, Cecconi S, Balestracci T, Caravaglios G. Robotics in general surgery: personal experience in a large community hospital. Arch Surg. 2003;138:777-784.

2. Chen PD, Wu CY, Hu RH, Ho CM, Lee PH, Lai HS, Lin MT, Wu YM. Robotic liver donor right hepatectomy: a pure, minimally invasive approach. Liver Transpl. 2016;22:1509-1518.

3. Rosales A, Salvador JT, Urdaneta G, Patino D, Montlleo M, Esquina S,
Caffaratti J, Ponce de Leon J, Guirado L, Villavicencio H. Laparoscopic kidney transplantation. Eur Urol. 2010;57:164167.

4. Tzvetanov I, Bejarano-Pineda L, Giulianotti PC, Jeon H, Garcia-Roca R, Bianco F, Oberholzer J, Benedetti E. State of the art of robotic surgery in organ transplantation. World JSurg. 2013;37:2791-2799.

5. Ibrahim HN, Foley R, Tan L, et al. Longterm consequences of kidney donation. $\mathrm{N}$ Engl J Med. 2009 Jan 29;360(5):459-469.

6. Ratner LE, Ciseck LJ, Moore RG, Cigarroa FG, Kaufman HS, Kavoussi LR. Laparoscopic live donor nephrectomy. Transplantation. 1995 Nov 15;60(9):1047-1049.

7. Eng M. The role of laparoscopic donor nephrectomy in renal transplantation. Am Surg. 2010 Apr;76(4):349-353.

8. Schweitzer EJ, Wilson J, Jacobs $S$, et al. Increased rates of donation with laparoscopic donor nephrectomy. Ann Surg. 2000 Sep;232(3):392-400.

9. Horgan S, Vanunu D, Benedetti E. Early experience with robotically assisted laparoscopic donor nephrectomy. Surg Laparosc Endosc Percutan Tech. 2002 Feb;12(1):64-70.

10. Hubert J, Renoult E, Mourey E, Format L, Cormier L, Kessler M. Complete roboticassistance during laparoscopic living donor nephrectomies: an evaluation of 38 procedures at a single site. Int J Urol. 2007 Nov;14(11):986-989.

11. Horgan S, Vanunu D. Robots in laparoscopic surgery. J Laparoendosc Adv Surg Tech A. 2001 Dec;11(6):415-419.

12. Horgan S, Vanunu D, Sileri P, Cicalese L, Benedetti E. Robotic-assisted laparoscopic donor nephrectomy for kidney transplantation. Transplantation. 2002 May 15;73(9):1474-1479.

13. Renoult E, Hubert J, Ladrière $M$, et al. Robot-assisted laparoscopic and open livedonor nephrectomy: a comparison of donor morbidity and early renal allograft 
outcomes. Nephrol Dial Transplant. 2006 Feb;21(2):472-477.

14. Janki S, Klop KWJ, Hagen SM, Terkivatan T, Betjes MGH, Tran TCK, Ijzermans JNM. Robotic surgery rapidly and successfully implemented in a high volume laparoscopic center on living kidney donation. Int J Med Robot. 2017;13:10.

15. Bhattu AS, Ganpule A, Sabnis RB, Murali V, Mishra S, Desai M. Robot-assisted laparoscopic donor nephrectomy vs standard laparoscopic donor nephrectomy: a prospective randomized comparative study. J Endourol. 2015;29:1334-1340.

16. Collins AJ, Foley RN, Gilbertson DT, Chen S-C. The United States Renal Data System public health surveillance of chronic kidney disease and endstage renal disease. Kidney Int Suppl 2015; 5: 2-7

17. Wagenaar S, Nederhoed JH, Hoksbergen AWJ, Bonjer HJ, Wisselink W, van Ramshorst GH. Minimally invasive, laparoscopic, and robotic-assisted techniques versus open techniques for kidney transplant recipients: a systematic review. Eur Urol. 2017;72:205217. [PubMed] [Google Scholar]

18. Herrell SD, Smith JA. Laparoscopic and robotic radical prostatectomy: what are the real advantages? BJU Int 2005; 95: 3-4

19. Territo A, Mottrie A, Abaza R, et al. Robotic kidney transplantation: current status and future perspectives. Minerva Urol Nefrol 2017; 69: 5-13

20. Breda A, Gausa L, Territo A et al. Roboticassisted kidney transplantation: our first case. World J Urol 2016; 2015: 443-7

21. Breda A, Territo A, Gausa $L$ et al. Robotic kidney transplantation: one year after the beginning. World J Urol 2017; 35: $1507-15$

22. Stadler P, Dvoracek L, Vitasek $P$, Matous P. Robot-assisted aortic and non-aortic vascular operations. J Vasc Surg 2016; 64: 537

23. Giulianotti P, Gorodner V, Sbrana F et al. Robotic transabdominal kidney transplantation in a morbidly obese patient. Am J Transplant 2010; 10: 147882

24. Boggi U, Vistoli $F$, Signori $S$ et al. Robotic renal transplantation: first European case. Transpl Int 2011; 24: 213 8

25. Menon M, Sood A, Bhandari $M$ et al. Robotic kidney transplantation with regional hypothermia: a step-by-step description of the Vattikuti Urology Institute-Medanta Technique (IDEAL Phase 2a). Eur Urol 2014; 65: 991-1000

26. Doumerc N, Roumiguie M, Rischmann P, Sallusto F. Totally robotic approach with transvaginal insertion for kidney transplantation. Eur Urol 2015; 68: 1103-4

27. Breda A, Territo A, Gausa L et al. Robotassisted kidney transplantation: the European Experience. Eur Urol 2018; 73: 273-81

28. Marzouk K, Lawen J, Alwayn I, Kiberd BA. The impact of vascular anastomosis time on early kidney transplant outcomes. Transplant Res. 2013;2:8.

29. Tsai MK, Lee CY, Yang CY, Yeh CC, Hu RH, Lai HS. Robot-assisted renal transplantation in the retroperitoneum. Transpl Int. 2014;27:452-457.

30. Laplace B, Ladriere $M$, Claudon $M$, Eschwege P, Kessler M, Hubert J. Robotic-assisted laparoscopic living donor nephrectomy: preoperative assessment and results of 100 cases. Prog Urol. 2014;24:288-293.

31. Lynch RJ, Ranney DN, Shijie C, Lee DS, Samala N, Englesbe MJ. Obesity, surgical site infection, and outcome following renal transplantation. Ann

Surg. 2009;250:1014-1020.

32. Orvieto MA, Chien GW, Shalhav AL, Tolhurst SR, Rapp DE, Galocy RM, Harland RC. Case report: robot-assisted laparoscopic pyeloureterostomy in a transplanted kidney with a ureteral stricture. J Endourol. 2006;20:31-32.

33. Kaouk JH, Spana G, Hillyer SP, White MA, Haber GP, Goldfarb D. Roboticassisted laparoscopic partial nephrectomy 
for a 7-cm mass in a renal allograft. Am J Transplant. 2011;11:2242-2246.

34. Mulloy MR, Tan M, Wolf JH, D'Annunzio SH, Pollinger HS. Robotic trans-abdominal transplant nephrectomy for a failed renal allograft. Am $\mathbf{J}$ Transplant. 2014;14:2883-2886.
35. Polcari AJ, Allen JC, Nunez-Natera's R, Mmeje CO, Andrews PE, Milner JE, Castle EP, Woods ME. Multicenter experience with robot-assisted radical prostatectomy in renal transplant recipients. Urology. 2012;80:1267-1272. 